\title{
Neutral solar photo-Fenton degradation of 4-nitrophenol on iron-enriched hybrid montmorillonite-alginate beads (Fe-MABs)
}

\author{
Salvatore Barreca ${ }^{a, b}$, Julia Janeth Velez Colmenares ${ }^{c}$, Andrea Pace $^{a, b, * *}$, \\ Santino Orecchio ${ }^{\mathrm{a}}$, Cesar Pulgarin ${ }^{\mathrm{c}, *}$ \\ a Dipartimento di Scienze e Tecnologie Biologiche, Chimiche e Farmaceutiche (STEBICEF), Università di Palermo, Viale delle Scienze, I-90128 Palermo, Italy \\ ${ }^{\mathrm{b}}$ Istituto EuroMediterraneo di Scienza e Tecnologia (IEMEST), Via Emerico Amari 123, 90139 Palermo, Italy \\ ${ }^{\mathrm{c}}$ Institute of Environmental Engineering, Laboratory for Environmental Biotechnology, Swiss Federal Institute of Technology - École Politechnique Fédérale \\ de Lausanne (EPFL), CH-1015 Lausanne, Switzerland
}

\section{A R T I C L E I N F O}

\section{Article history:}

Received 18 December 2013

Received in revised form 10 February 2014

Accepted 22 February 2014

Available online 16 March 2014

\section{Keywords:}

Iron alginate beads

Montmorillonite

Photodegradation

Photo-Fenton

4-Nitrophenol

\begin{abstract}
A B S T R A C T
Hybrid montmorillonite-alginate beads (MABs) were prepared by the ion-gelation method from alginate and montmorillonite clay suspension dropped in a calcium chloride solution. Similarly, iron-enriched beads (Fe-MABs) were prepared using iron-exchanged montmorillonite. All beads were characterized by atomic absorption and Fourier-transform infrared spectroscopy. The efficiency of Fe-MABs as catalysts for the solar photo-Fenton performed at initial $\mathrm{pH}=7.0$ was evaluated by varying the catalyst amount and hydrogen peroxide concentration, and monitoring the removal of 4-nitrophenol (4-NP) at initial concentration of $10 \mathrm{ppm}$. A kinetic analysis showed that the removal of 4-NP by Fe-MABs followed a pseudo first-order kinetics model $\left(R^{2}=0.966\right)$.

High 4-NP removal (75\%) was achieved with 25 Fe-MABs by using 150 ppm of hydrogen peroxide and 40 min of irradiation, while total 4-NP removal was obtained by using 500 ppm of hydrogen peroxide. Moreover, preliminary studies about beads' recycling showed good removal efficiencies for the first three cycles.
\end{abstract}

(C) 2014 Elsevier B.V. All rights reserved.

\section{Introduction}

Along with the development of industrial production, both the amount and categories of hazardous pollutants are enlarging [1-3]. In this frame, typical non-biodegradable, toxic and bio-refractory pollutants are nitro-aromatics compounds. One of the most dangerous nitro-aromatics is 4-nitrophenol (4-NP), which is largely present in the wastewaters as a by-product of pesticide, herbicide and synthetic dyes production [4]. 4-NP can cause considerable damages to the ecosystem and human health, causing alterations in the central nervous system, liver, kidney and blood of humans and animals [5]. The conventional methods in industrial wastewater treatment are biological oxidation [6] and physico-chemical

\footnotetext{
* Corresponding author. Tel.: +41 02169347 20; fax: +41 0216935690. ** Corresponding author at: Dipartimento di Scienze e Tecnologie Biologiche, Chimiche e Farmaceutiche (STEBICEF), Università di Palermo, Viale delle Scienze, I-90128 Palermo, Italy. Tel.: +39 091 23897543; fax: +39 091596825.

E-mail addresses: andrea.pace@unipa.it (A. Pace), cesar.pulgarin@epfl.ch, lusifer68@gmail.com (C. Pulgarin).
}

processes [7]. Biological processes, however, are not efficient for 4-NP removal due to its high stability and solubility in water [7]. On the other hand, non-destructive removal of 4-NP by physico-chemical processes would result in the transfer of the contamination from one phase to another, thus producing secondary wastes still needing further treatment [8]. For this reason the research community is focused about the development of processes for pollutants removal and degradation by harmless and inexpensive techniques [9]. In the last few decades, also photochemical methodologies have been applied to pollutants degradation in air and aqueous matrices $[10,11]$ as well as for the refinement of analytical procedures [12].

In this context, Advanced Oxidation Processes (AOPs) have potential in wastewater treatment for completely removing organic pollutants [13]. These processes depend on the generation of hydroxyl radicals $(\bullet \mathrm{OH})$ which are more effective oxidants $\left(E^{0}=+2.8 \mathrm{~V}\right)$ ozone $\left(E^{0}=+2.0 \mathrm{~V}\right)$ and $\mathrm{H}_{2} \mathrm{O}_{2}\left(E^{0}=+1.8 \mathrm{~V}\right)$.

One of the most effective AOPs involves the Fenton's reaction (equations from (1) to (7)), where hydrogen peroxide is catalytically decomposed into various reactive oxygenated species (ROS) by both ferrous (Eq. (1)) and ferric (Eq. (2)) ions, usually in an acidic 
(2.8-5.5) $\mathrm{pH}$ range, and with an optimal efficiency at $\mathrm{pH}=3.2$ [13]. Overall, the organic contaminants will be oxidatively degraded by the formed ROS (mainly the hydroxyl radical) at the expenses of hydrogen peroxide consumption.

$$
\begin{aligned}
& \mathrm{Fe}^{2+}+\mathrm{H}_{2} \mathrm{O}_{2} \rightarrow \mathrm{Fe}^{3+}+\mathrm{OH}^{-}+\bullet \mathrm{OH} \quad\left(k=63 \mathrm{~L} \mathrm{~mol}^{-1} \mathrm{~s}^{-1}\right) \\
& \mathrm{Fe}^{3+}+\mathrm{H}_{2} \mathrm{O}_{2} \rightarrow \mathrm{Fe}^{2+}+\mathrm{HO}_{2} \bullet+\mathrm{H}^{+} \quad\left(k=3.1 \times 10^{-3} \mathrm{~L} \mathrm{~mol}^{-1} \mathrm{~s}^{-1}\right) \\
& \bullet \mathrm{OH}+\mathrm{H}_{2} \mathrm{O}_{2} \rightarrow \mathrm{HO}_{2} \bullet+\mathrm{H}_{2} \mathrm{O} \quad\left(k=3.3 \times 10^{7} \mathrm{~L} \mathrm{~mol}^{-1} \mathrm{~s}^{-1}\right) \\
& \bullet \mathrm{OH}+\mathrm{Fe}^{2+} \rightarrow \mathrm{Fe}^{3+}+\mathrm{OH}^{-} \quad\left(k=3.0 \times 10^{8} \mathrm{~L} \mathrm{~mol}^{-1} \mathrm{~s}^{-1}\right) \\
& \mathrm{Fe}^{3+}+\mathrm{HO}_{2}^{\bullet} \rightarrow \mathrm{Fe}^{2+}+\mathrm{O}_{2}+\mathrm{H}^{+} \quad\left(k=2.0 \times 10^{3} \mathrm{~L} \mathrm{~mol}^{-1} \mathrm{~s}^{-1}\right) \\
& \mathrm{Fe}^{2+}+\mathrm{HO}_{2}^{\bullet}+\mathrm{H}^{+} \rightarrow \mathrm{Fe}^{3+}+\mathrm{H}_{2} \mathrm{O}_{2} \quad\left(k=1.2 \times 10^{6} \mathrm{~L} \mathrm{~mol}^{-1} \mathrm{~s}^{-1}\right)(6) \\
& \mathrm{HO}_{2}^{\bullet}+\mathrm{HO}_{2}^{\bullet} \rightarrow \mathrm{H}_{2} \mathrm{O}_{2}+\mathrm{O}_{2} \quad\left(k=8.3 \times 10^{5} \mathrm{~L} \mathrm{~mol}^{-1} \mathrm{~s}^{-1}\right)
\end{aligned}
$$

In the photochemical variant of the Fenton's reaction (photoFenton), the production of hydroxyl radical $(\bullet \mathrm{OH})$ is greatly increased by UV-vis irradiation in the $200-600 \mathrm{~nm}$ wavelength range [13].

Under homogeneous conditions, ROS start to be photochemically produced at around $\mathrm{pH} 5.2$, while a range of $\mathrm{pH} 2.5-3.5$ is required for optimal efficiency [14]. This represents one of the limitations of the application of Fenton processes and current research is aimed at finding new Fenton-like heterogeneous processes able to begin under neutral conditions. To avoid environmental issues due to the consumption, precipitation, and treatment of a large amount of iron, attempts have been made to immobilize Fe ions on polymeric substrates, such as Nafion membranes [15] and pellets [16]. However, considering the cost of Nafion on a large scale [16], various low cost polymeric materials, which have also the capability of adsorbing inorganic and organic pollutants, are being explored as support for heterogeneous photo-Fenton reactions $[17,18]$. For instance, Fe(III) ions have been immobilized onto modified polyacrylonitrile fibers $[19,20]$ and alginate $[21,21]$. The latter, is a biopolymer exhibiting a sol-gel transition when exposed to different ionic environment (e.g. substitution of sodium by calcium or iron cations). This material is biocompatible, inexpensive, and is easily assembled into spherules or beads [22]. However, the replacement of calcium cations in the alginate matrix with the catalytic iron species would significantly decrease the bead stability $[23,24]$. Recently, mesoporous inorganic materials, such as alumina silicates clays (montmorillonite, halloysite), have been used to obtain hybrid gel beads with improved stability $[18,25,26]$. However, the low iron concentration in the natural clay has limited their use in photo-Fenton reaction [27]. Moreover, after some pioneering report [21], that underlined the effect of Fe-alginate beads to conduce the photo-Fenton reaction at neutral $\mathrm{pH}$, the application of iron-containing alginate beads as heterogeneous Fenton catalysts for the degradation of the organic pollutants, due their "big fragility" [23] and high iron leaching, seems to be still in its embryonic stage $[23,28]$. Therefore, we decided to explore the possibility of using iron-enriched clay for the construction of stable hybrid alginate/clay beads as catalyst for heterogeneous photo-Fenton. By considering recent studies reporting the adsorption of 4-NP pollutant onto hybrid montmorillonite/alginate beads (MABs) [29] and the possibility to increase the iron content of the clay by ion exchange, we decided to prepare and characterize iron-enriched montmorillonite/alginate beads (Fe-MABs), and test them as heterogeneous catalysts for the photo-Fenton degradation of 4-NP as model pollutant.

\section{Experimental}

\subsection{Materials and reagents}

Sodium alginate was obtained from Fischer Scientific and used without purification. Iron (III) nitrate heptahydrate was purchased from Fluka. Formic acid, ethanol, and 4-nitrophenol were purchased from Merck. Sodium bisulphite, hydrogen peroxide (33\%), calcium chloride, montmorillonite K10 (Mont-K) clay, and titania oxisulfate were purchased from Sigma Aldrich. All solutions were prepared with Milli-Q water $(18.2 \mathrm{M} \Omega \mathrm{cm})$. Glassware for analytical analysis and reactors were soaked for one day in $10 \% \mathrm{HNO}_{3}$ after each experiment to prevent iron cross-contamination.

\subsection{Preparation of iron-enriched montmorillonite (Fe-Mont)}

Fe-Mont has been prepared by following the recently reported methodology [30]. By following the reported procedure, the iron will be present in goethite form $(\alpha-\mathrm{FeOOH})$ without $\mathrm{Fe}_{2} \mathrm{O}_{3}$ or $\mathrm{Fe}_{3} \mathrm{O}_{4}$ species $[30,31]$. A30\% $(\mathrm{w} / \mathrm{w}) \mathrm{Fe}\left(\mathrm{NO}_{3}\right)_{3}$ solution was prepared in a $60 / 40(\mathrm{vol} / \mathrm{vol}$ ) ethanol/water solvent mixture. Mont-K (5 g) was added to the ferric nitrate solution and the slurry was stirred at room temperature for $4 \mathrm{~h}$. The obtained slurry was centrifuged, and the residue washed with water and dried at $120^{\circ} \mathrm{C}$ for $24 \mathrm{~h}$ thus yielding a fine powder of Fe-Mont.

\subsection{Preparation of hybrid montmorillonite-alginate beads (MABs)}

Hybrid alginate beads were prepared by adapting the ionic gelation method [32]. In particular, montmorillonite/alginate beads (MABs) were prepared according to the procedure reported in the literature [29]. In turn, hybrid iron-enriched montmorillonitealginate beads (Fe-MABs) were prepared by mixing a $4 \%(\mathrm{w} / \mathrm{v})$ sodium alginate aqueous solution $(0.8 \mathrm{~g}$ in $20 \mathrm{~mL})$ with a $20 \mathrm{~mL}$ aqueous suspension of Fe-Mont $(1.6 \mathrm{~g})$. The resulting slurry was stirred at room temperature for $2 \mathrm{~h}$ and then added drop wise into a stirred solution of $0.1 \mathrm{M} \mathrm{CaCl}_{2}(100 \mathrm{~mL})$ forming about 600 red-ochre gel beads with approximate diameter of $5 \mathrm{~mm}$. The beads suspension was left under continuous stirring for $10 \mathrm{~h}$ before removing the calcium chloride solution by filtration. The beads were then re-suspended in Milli-Q water $(100 \mathrm{~mL})$, stirred for $1 \mathrm{~h}$ and filtered. All beads underwent five washing cycles before being stored in water at $5^{\circ} \mathrm{C}$.

\subsection{Iron content determination in MABs and Fe-MABs}

In order to determine the iron content immobilized on the surface of MABs and Fe-MABs analytical procedures were conducted as reported in literature [23] on 50 beads randomly taken from a 600 -beads batch. The 50 -beads sample (removed by filtration on a Whatman 4 filter paper from the stock solution) was added to a $2 \mathrm{M} \mathrm{H}_{2} \mathrm{SO}_{4}$ aqueous solution $(25 \mathrm{~mL})$ and stirred at room temperature for $24 \mathrm{~h}$ to allow the release of superficial Iron (III) ions. The concentration of $\mathrm{Fe}^{3+}$ in the solution was determined by AAS. The total iron content of the hybrid beads was determined on a different 50 -beads sample selected from the same 600-beads batch. The sample was filtered from the stock solution, weighted, placed in a crucible and dried at $60^{\circ} \mathrm{C}$ for $12 \mathrm{~h}$, an finally heated in a muffle using a two-step temperature program $\left(20-250^{\circ} \mathrm{C}\right.$ for $2 \mathrm{~h}$ followed by a fast ramp and hold for $24 \mathrm{~h}$ at $550^{\circ} \mathrm{C}$ ). Once cooled, a $25 \mathrm{~mL}$ $20 \%(\mathrm{v} / \mathrm{v})$ nitric acid was added to dissolve the ashes. The obtained acidic suspension was filtered on a Whatman 4 filter paper and analyzed by AAS. Iron determinations were repeated for three times 
Table 1

Weight of beads wet and dried and iron concentration in surface and total in MABs and Fe-MABs.

\begin{tabular}{lcc}
\hline Parameters & 50 MABs & 50 Fe-MABs \\
\hline Weight of beads wet $(\mathrm{mg})$ & $2075 \pm 3$ & $2368 \pm 3$ \\
Weight of beads dried $(\mathrm{mg})$ & $192 \pm 1$ & $206 \pm 1$ \\
Fe in surface $(\mathrm{mg})$ & $<0.2$ & $2.2 \pm 0.1$ \\
Fe in total $(\mathrm{mg})$ & $0.4 \pm 0.1$ & $2.8 \pm 0.1$ \\
\hline
\end{tabular}

within the same batch and performed for two batches of MABs and Fe-MABs. Results are reported in Table 1.

\subsection{Irradiation experiments}

Both photochemical (without beads) and photocatalytic experiments were carried out in two Pyrex glass reactors, each containing $25 \mathrm{~mL}$ of $2.8 \mathrm{mM}(10 \mathrm{ppm})$ aqueous nitrophenol solution, resembling the typical concentration of this micropollutant class in pharmaceutical industries wastewater [33]. Initial $\mathrm{pH}$ was adjusted at $7.0 \pm 0.1$, and the solution was irradiated in batch mode in a solar simulator Suntest CPS (Atlas GmbH) at 290-600 nm under continuous stirring (300 rpm). A Xenon arc lamp was used as a light source with an irradiation intensity of $1800 \mathrm{~W} / \mathrm{m}^{2}$. The average of the irradiation intensity was monitored in the range $300-400 \mathrm{~nm}$ by an ACADUS S2004 UV radiometer equipped with a LS-3300 controller. The temperature reached in the reactor during the experiments was in the range $25-35^{\circ} \mathrm{C}$. Experiments were performed by varying the initial amount of $\mathrm{H}_{2} \mathrm{O}_{2}(0-500 \mathrm{ppm})$, the type (MABs or Fe-MABs) and the amount of beads ( $0-0.617 \mathrm{~g} ; 0-150$ beads). Reactions were monitored at various irradiation times by collecting small portions $(0.5 \mathrm{~mL})$ of the irradiated solution and results are illustrated in the 0-60 min range. To avoid dark Fenton reactions during the time allowed for nitrophenol analysis, the residual $\mathrm{H}_{2} \mathrm{O}_{2}$ in each collected sample was quenched by addition of an excess of $1 \mathrm{M}$ sodium bisulfite immediately after sampling.

\subsection{Analytical methods}

FT-IR measurements were performed in freeze-drying samples with $\mathrm{KBr}$ pellets. The FT-IR spectrum were registers in the range from 500 to $4000 \mathrm{~cm}^{-1}$ by using an FT-IR instrument Agilent Cary 630 FT-IR Spectrophotometer.

The 4-NP degradation and nitrophenol reaction products were monitored by chemical standards retention time's comparison by HPLC (HP Hewlett Packard 1100 Series: detector Agilent 1100 Series) equipped with a C-18 analytical column (Macherey-Nagel Necleosil 100-5 c18), using a 1:1 acetonitrile/aqueous formic acid (0.5\%) mobile phase, a flow rate of $0.5 \mathrm{~mL} / \mathrm{min}$, and monitoring UV absorption at $300 \mathrm{~nm}$.

The dissolved iron concentration was measured by atomic absorption spectroscopy (AAS) (Perkin Elmer Ltd., Beaconsfield, UK) according to the UNI-EN-ISO 11885 method. The $\mathrm{H}_{2} \mathrm{O}_{2}$ concentration in solution was assessed by titania oxisulfate method (modified method DIN $38402 \mathrm{H} 15$ ) monitoring absorbance at $410 \mathrm{~nm}$ using UV-VIS spectrophotometer (Perkin Elmer Lambda 20). pH was monitored by a Toledo S220 pH-meter.

\section{Results and discussion}

\subsection{Characterization of MABs}

The formation of hybrid beads, such as reported in literature, could be driven by polar interactions between the uncharged siloxane moieties of the clay and the hydroxyl groups of the alginate biopolymer [26]. Compared to normal montmrillonite-alginate a

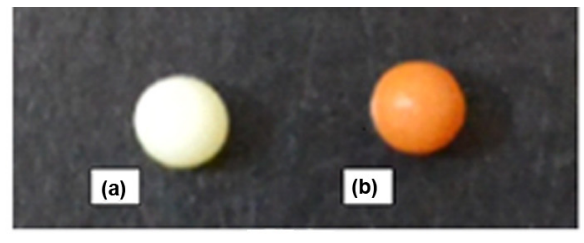

b
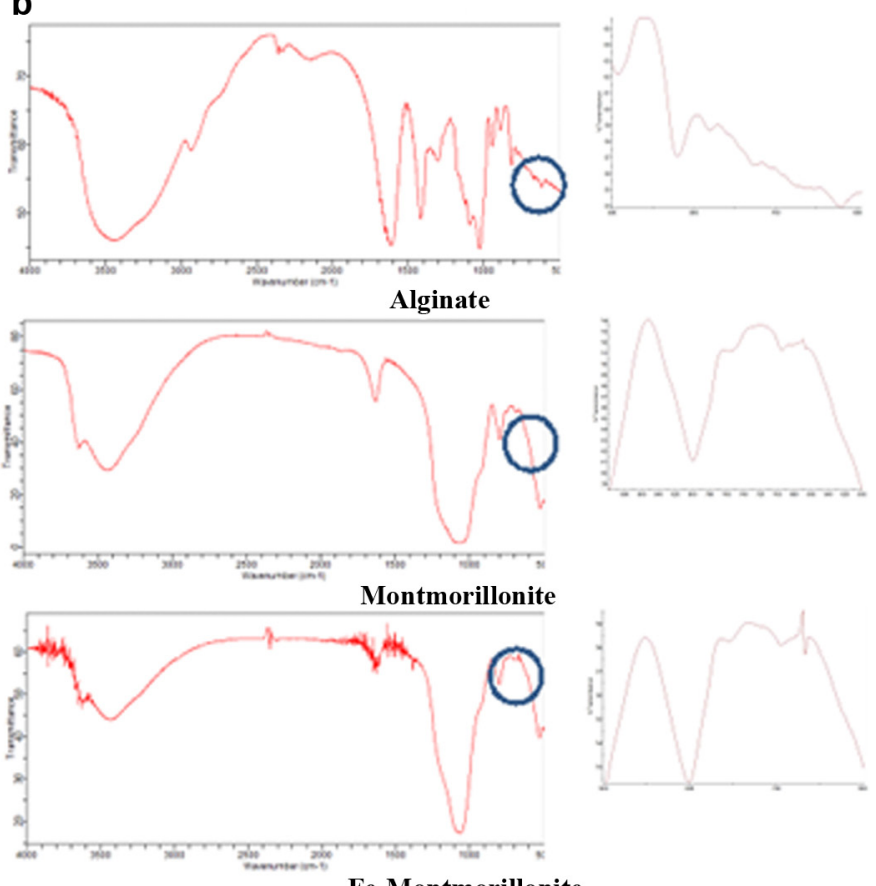

Fe-Montmorillonite
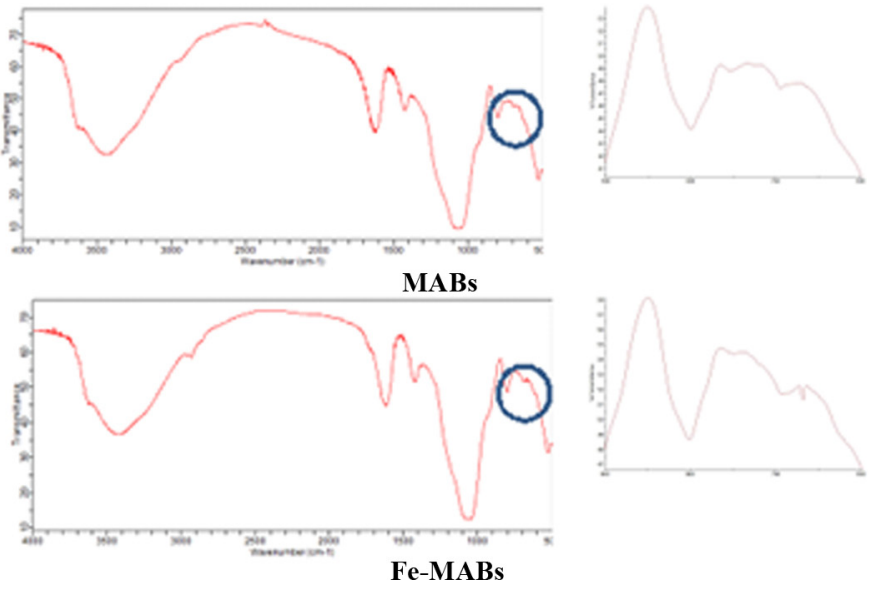

Fig. 1. (a) Pictures of different alginate beads (a) Ca-alginate montmorillonite bead; (b) Ca-alginate Fe-enriched montmorillonite bead. (b) FTIR spectra of alginate; montmorillonite; Fe-montmorillonite; MABs; Fe-MABs.

beads, the introduction of Fe-enriched montmorillonite into alginate capsules was accompanied by a significant change in color of the beads, from white to red, easily detectable by the naked eye (Fig. 1).

Weight of both wet and dried beads is reported in Table 1 for sets of 50 beads which were also characterized for their content of iron concentration on the surface and in the entire bead.

The drying process induced shrinkage of the microcapsules in fact the weight loss during the drying process was $91 \%$ for Fe-MABs and $90 \%$ for MABs (Table 1 ).

Iron concentration in MABs surface is not detectable $(<0.2 \mathrm{mg}$ or $<520 \mathrm{mg} / \mathrm{kg}$ ) while superficial iron on the Fe-MABs is $2.2 \mathrm{mg}$ or 
$10,500 \mathrm{mg} / \mathrm{kg}$. Fe content in total MABs is $0.4 \mathrm{mg}(2083 \mathrm{mg} / \mathrm{kg})$. This value is very low respect the Fe-MABS that is $2.8 \mathrm{mg}(13,000 \mathrm{mg} / \mathrm{kg})$.

The differences and molecular interactions of montmorillonite Fe enriched and alginate beads were investigated by using FTIR spectroscopy. The FTIR spectrum of alginate, montmorillonite k10, montmorillonite Fe-enriched, MABs and Fe-MABs are shown in Fig. $1 \mathrm{~b}$.

The absorption bands from FT-IR of montmorillonite were assigned as follows: 3450 and $3631 \mathrm{~cm}^{-1}$ corresponded to $\mathrm{OH}$ stretching mode in molecular water and $\mathrm{Si}-\mathrm{OH}, \mathrm{Al}-\mathrm{OH}$ bonds; $2900 \mathrm{~cm}^{-1}$ corresponded to $\mathrm{C}-\mathrm{H}$ stretching; 1623 and $1428 \mathrm{~cm}^{-1}$ corresponded to carboxylate asymmetric/symmetric; 1044, 623 and $523 \mathrm{~cm}^{-1}$ to $\mathrm{Si}-\mathrm{O}$ stretching in $[\mathrm{SiO}]^{4-}$ tetrahedra; $916 \mathrm{~cm}^{-1}$ was attributed to $\mathrm{Al}-\mathrm{Al}-\mathrm{OH}$ bending vibration; $798 \mathrm{~cm}^{-1}$ corresponded to $\mathrm{Si}-\mathrm{O}$ in $\mathrm{SiO}_{2} ; 669 \mathrm{~cm}^{-1}$ corresponded to $\mathrm{Fe}-\mathrm{OH}$ stretching mode of goethite in agree with literature reported [34]. The absorption bands at 1623 and $1428 \mathrm{~cm}^{-1}$ confirm the presence of alginate in both MABs and Fe-MABs, while the adsorption band at $669 \mathrm{~cm}^{-1}$, confirms the presence of iron in its goethite form both into iron enriched montmorillonite and Fe-MABs.

\subsection{Photocatalytic activity of MABs and Fe-MABs}

To evaluate the photocatalytic activities of alginate/montmorillonite hybrid beads, 4-NP degradation studies have been conducted under simulated solar light at initial $\mathrm{pH}$ $7.0 \pm 0.1$ using either MABs (25 wet beads; $0.096 \mathrm{~g}$ dry weight) or Fe-MABs ( 25 wet beads; $0.103 \mathrm{~g}$ dry weight). In our case, employing the same number of beads, we compared the similar surface area and weight for different beads. The catalytic activities were determined by considering 4-NP degradation and $\mathrm{H}_{2} \mathrm{O}_{2}$ consumption (Fig. 2a and b).

Data illustrated in Fig. 2b clearly show the increased rate of $\mathrm{H}_{2} \mathrm{O}_{2}$ consumption when Fe-MABs are used with respect to MABs or solution irradiation.

As expected, 4-NP was highly stable under solution irradiation without hydrogen peroxide and catalyst (Fig. 2a, purple line). The photochemical irradiation in the presence of $\mathrm{H}_{2} \mathrm{O}_{2}$, instead caused the degradation of 4-NP with a pseudo-first order kinetic constant $(k)$ whose value is $=0.0047 \pm 0.0006\left(\mathrm{~min}^{-1}\right)$. This photooxidative degradation could be ascribed to either ROS generation by energy transfer mechanisms sensitized by the deprotonated 4-nitrophenol, which absorbs at $418 \mathrm{~nm}$ and at neutral $\mathrm{pH}$ is equimolar to its undissociated form [35], or to the direct homolytic photolysis of $\mathrm{H}_{2} \mathrm{O}_{2}$ induced by UV absorption. However, considering both the used concentrations of 4-NP and hydrogen peroxide and their molar extinction coefficients $\left(\varepsilon=0.7 \mathrm{M}^{-1} \mathrm{~cm}^{-1}\right.$ for $\mathrm{H}_{2} \mathrm{O}_{2}$ at $310 \mathrm{~nm}$ [36]; $\varepsilon=16,800 \mathrm{M}^{-1} \mathrm{~cm}^{-1}$ for $4-\mathrm{NP}$ at $410 \mathrm{~nm}$ [37]) one can reasonably hypothesize that the contribution of direct photolysis of $\mathrm{H}_{2} \mathrm{O}_{2}$ is negligible.

Interestingly, using hybrid MABs (see red line in Fig. 2a) does not improve the removal rate of nitrophenol possibly due to the complementary effects of (i) interference of the beads with light irradiation (reducing the amount of light reaching 4-NP for the photosensitized process), and (ii) adsorption of 4-NP on the MABs surface (increasing removal). On the other hand, by employing iron enriched Fe-MABs the 4-NP removal rate undergoes a great increase (Fig. 2, blue lines) due to the significant contribution of photo-Fenton processes and devoid of a lower 4-NP adsorption capacity of Fe-MABs with respect to MABs (see kinetics and adsorption isotherms in Fig. 3).

Since the degradation of 4-NP involves both ${ }^{\bullet} \mathrm{OH}$ and $\mathrm{HO}_{2}$ • radicals, the processes implicated in their generation in the presence of Fe-MABs (heterogenous photo-Fenton) are illustrated in Scheme 1a, while their consumption is summarized in Scheme 1b.

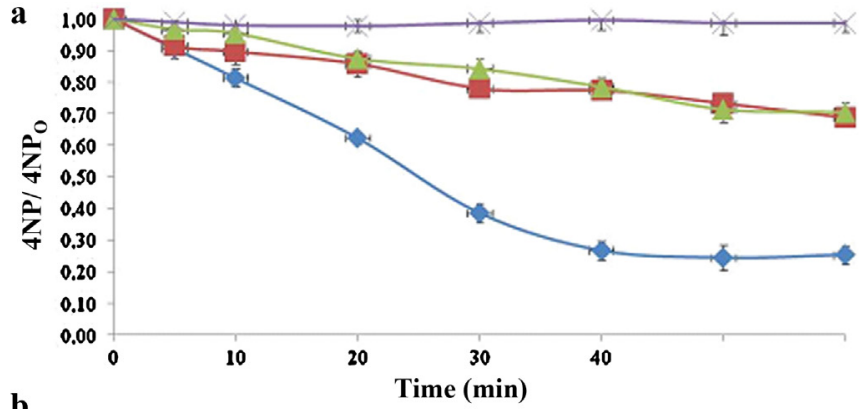

b

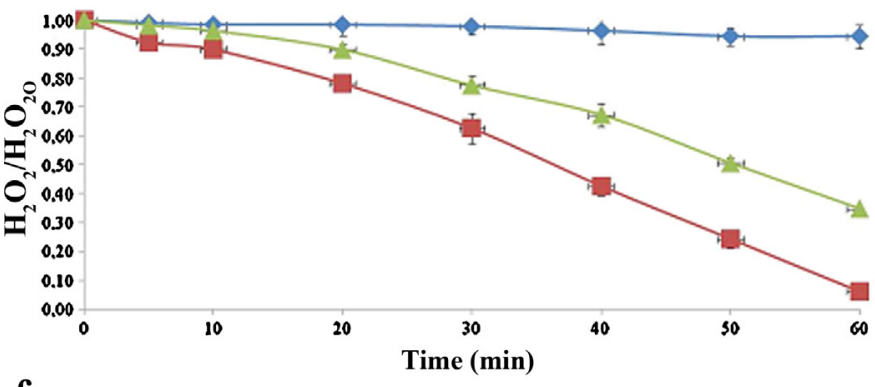

c

Fig. 2. (a) $[4-\mathrm{NP}]$ variation under irradiation at initial $\mathrm{pH}_{0}=7.0,[4-\mathrm{NP}]_{0}=2.8 \mathrm{mM}$ (10 ppm) - $\times$ - (purple line); [4-NP] variation under irradiation at initial $\mathrm{pH}_{0}=7.0$, $[4-\mathrm{NP}]_{0}=2.8 \mathrm{mM}(10 \mathrm{ppm}),\left[\mathrm{H}_{2} \mathrm{O}_{2}\right]_{0}=0.176 \mathrm{M}(150 \mathrm{ppm})$. Solution in the presence of $\left[\mathrm{H}_{2} \mathrm{O}_{2}\right]_{0}=0.176 \mathrm{M}(150 \mathrm{ppm})$ : Solution $-\Delta$ - (green line); 25 MABs suspension $\square$ - (red line); 25 Fe-MABs suspension $-\diamond$ - (blue line). (b) $\left[\mathrm{H}_{2} \mathrm{O}_{2}\right]$ variation during 4-NP degradation at initial $\mathrm{pH}_{0}=7.0,[4-\mathrm{NP}]_{0}=2.8 \mathrm{mM}(10 \mathrm{ppm}),\left[\mathrm{H}_{2} \mathrm{O}_{2}\right]_{0}=0.176 \mathrm{M}$ (150 ppm). Solution $-\Delta$ - (green line); 25 MABs suspension - $\square$ - (red line); $25 \mathrm{Fe}-$ MABs suspension $-\diamond$ - (blue line). (c) $\mathrm{pH}$ profiles during 4-NP degradation $\mathrm{pH}_{0}=7.0$ $\left([4-\mathrm{NP}]_{0}=10 \mathrm{ppm}(2.8 \mathrm{mM}),\left[\mathrm{H}_{2} \mathrm{O}_{2}\right]=150 \mathrm{ppm}(176.47 \mathrm{mM})\right.$ in the different conditions Fe-MABs 4.0 ppm, MABs 3.8 ppm: $-\times-h v$; $-\diamond-$ Fe-MABs $+h v+\mathrm{H}_{2} \mathrm{O}_{2}$; $-\square-$ MABs $+h v+\mathrm{H}_{2} \mathrm{O}_{2} ;-\Delta-h v+\mathrm{H}_{2} \mathrm{O}_{2}$. (For interpretation of the references to color in this figure legend, the reader is referred to the web version of the article.)

Overall, hydroxyl radicals $\bullet \mathrm{OH}^{\circ}$ are consumed by four different pathways resulting in: 4-NP oxidation products (Ia), alginate oxidation products (Ib), MAB-Fe ${ }^{3+}$ catalyst regeneration (Ic), and $\mathrm{HO}_{2}{ }^{\bullet}$ formation by reaction with hydrogen peroxide (Id).

In turn, hydroperoxide radicals $\mathrm{HO}_{2}$ are consumed by: 4-NP oxidation (IIa), alginate oxidation (IIb), a slow $\mathrm{H}_{2} \mathrm{O}_{2}$ mediated production of $\bullet \mathrm{OH}$ (IIc), and acid catalyzed $\mathrm{H}_{2} \mathrm{O}_{2}$ formation also accompanied by MAB-Fe ${ }^{3+}$ regeneration (Ic). This mechanism was confirmed by identifying the formation of hydroquinone and 4nitrocatechol which are further degraded to succinic and oxalic acids [37]. All reaction products have been detected by qualitative analysis performed by HPLC. Consequentially, the formation of these degradation products contributes to the change in medium acidity during the irradiation (see Fig. 2c).

In general, the removal of 4-NP from polluted water depends on physical removal (adsorption) and photochemical decomposition by either irradiation in the presence of $\mathrm{H}_{2} \mathrm{O}_{2}$ or photo-Fenton processes. In the considered heterogeneous media, 4-NP removal due 

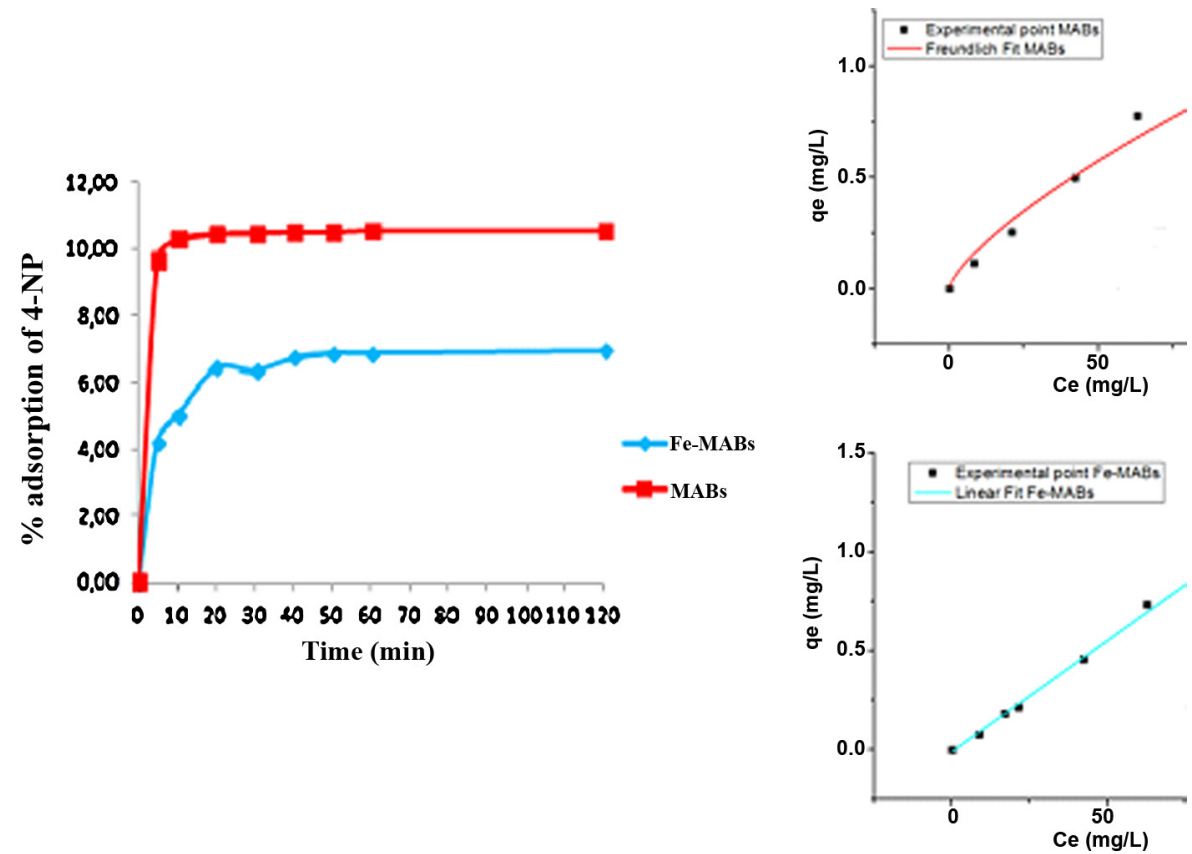

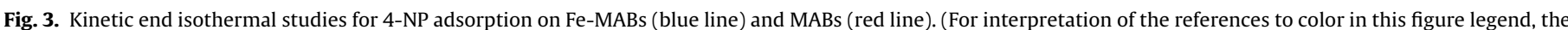
reader is referred to the web version of the article.)

to adsorption processes is slightly higher in the case of MABs (10\% adsorption) than for Fe-MABs (7\%). On the other hand, photodegradation of 4-NP by solution irradiation in the presence of hydrogen peroxide is not as efficient as heterogeneous irradiation performed in the presence of Fe-MABs.

Although the better performance of 4-NP removal obtained by Fe-MABs can be ascribed to the concurrence of several processes,

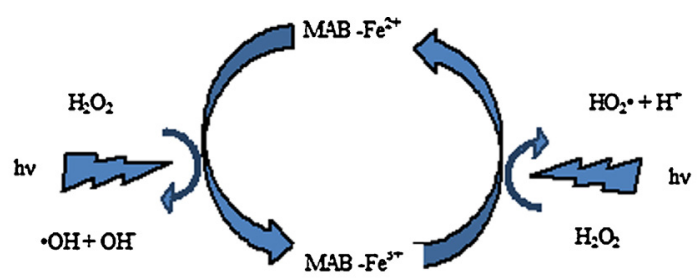

(a)

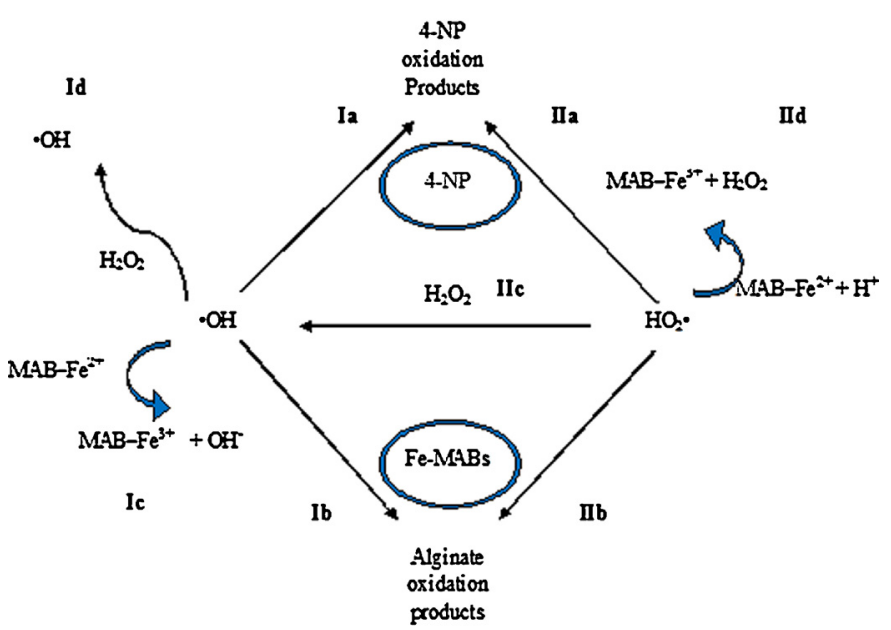

(b)

Scheme 1. (a) mechanism of $\bullet \mathrm{OH}$ and $\mathrm{HO}_{2} \bullet$ origination using Fe-MABs. (b) Consumption of ${ }^{\bullet} \mathrm{OH}$ and $\mathrm{HO}_{2} \bullet$ during 4 -NP photodegradation using $\mathrm{Fe}-\mathrm{MABs}$. by considering the low adsorption percentages, we can assume that the physical adsorption is not the principal mechanism for the 4NP removal in the heterogeneous conditions of the photo-Fenton process.

To evaluate the effect of each process involved in the 4NP removal during the irradiation in the presence of $\mathrm{H}_{2} \mathrm{O}_{2}$ and Fe-MABs, the contribution of adsorption, heterogeneous photodegradation, and photo-Fenton processes were estimated by equations from (8) to (10) and illustrated in Fig. 4.

In detail, the loading experiments demonstrated that using MABs and Fe-MABs the adsorption equilibrium is rapidly reached after 5 and $10 \mathrm{~min}$, respectively (see red bar in Fig. 4). Under similar conditions used for irradiation, it is reasonable to assume that during the photodegradation of 4-NP in heterogeneous media, the degraded 4-NP can be quickly replaced by new 4-NP molecules on the bead's surface. Therefore, as a prudent approximation, we considered that physical adsorption during heterogeneous photodegradation (HPD) has a value similar to that observed during adsorption studies for the corresponding type and number of beads (Eqs. (8) and (9)).

adsmol4-NP ${ }_{t}=$ mol4- $\mathrm{NP}_{0}-\mathrm{mol}_{4}-\mathrm{NP}_{t}$

ads mol 4- $\mathrm{NP}_{t}^{\mathrm{HPD}} \approx$ ads mol 4-NP $t$

where mol 4-NP $\mathrm{N}_{0}$ is the initial number of 4-nitrophenol moles, mol $4-\mathrm{NP}_{t}$ is the number of 4-NP moles detected in solution at time $t$, ads mol 4-NP $t$ is the number of 4-NP moles adsorbed during the adsorption experiments at the time $t$, and ads mol $4-\mathrm{NP}_{t}^{\mathrm{HPD}}$ is the number of 4-NP moles adsorbed during the heterogeneous photodegradation at time $t$.

Since 4-NP is photostable in solution at the used wavelength (Fig. 2a, purple line), the contribution of non-Fenton photodegradation can only derive from sensitized $\mathrm{H}_{2} \mathrm{O}_{2}$ oxidation (see above). This contribution, can be estimated by considering the photochemical removal of 4-NP performed in the presence of MABs. In our approximation, we considered the MABs photo-Fenton as negligible ( $\mathrm{PF}$ mol $4-\mathrm{NP}_{t} \approx 0$ for $\mathrm{MABs}$ ) due to the extremely low content 

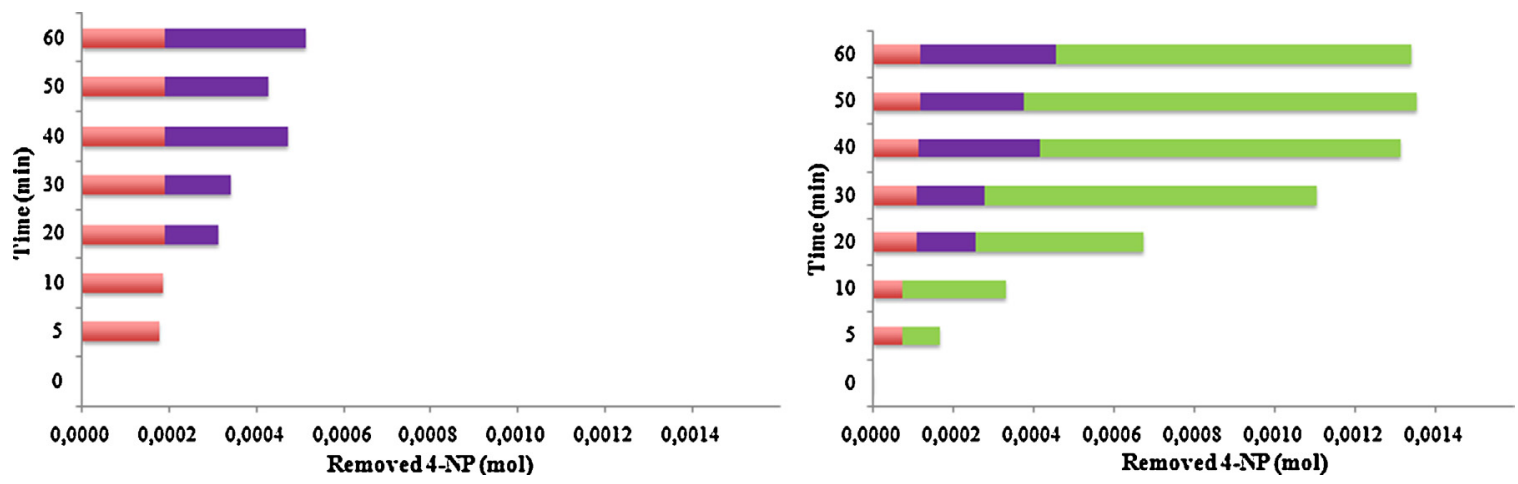

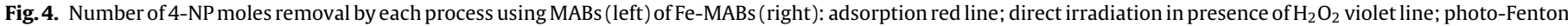
green line. (For interpretation of the references to color in this figure legend, the reader is referred to the web version of the article.)

of superficial iron on the surface of MABs beads (Table 1 and Eq. (8)).

$\mathrm{PF}$ mol 4-NP $=$ mol 4-NP $-\operatorname{mol} 4-\mathrm{NP}_{t}$

$$
\text { - ads mol 4-NP }- \text { non-PF mol 4-NP }{ }_{t}^{\mathrm{HPD}}
$$

where non-PF mol $4-N P_{t}^{H P D}$ is the number of 4-NP moles degraded at time $t$ by means of non-Fenton processes, and $\mathrm{PF}$ mol $4-\mathrm{NP}_{t}$ is the number of 4-NP moles degraded at time $t$ by means of iron catalyzed photo-Fenton processes.

This non-Fenton contribution to 4-NP removal has been considered similar for both experiments with MABs and Fe-MABs.

Consequentially, the photo-Fenton contribution to the removal of 4-NP during irradiation in the presence of $\mathrm{H}_{2} \mathrm{O}_{2}$ and Fe-MABs can be conservatively estimated by Eq. (10).

Results have been used to compare the efficiency of the two types of beads as illustrated in Fig. 4.

By Fig. 4 it is possible to prove that using the Fe-MABs the number of 4-NP moles removed by photochemical process is greater than MABs. These differences are detectable during the whole process.

Fig. 4 shows that using MABs, the 4-NP removal by adsorption process remain constant during the experiment (1.0 ppm), the non-Fenton photodegradation starts later than in solution, after approximately $20 \mathrm{~min}$ of irradiation, due the interference by beads with light (see violet bar in Fig. 4). On the other hand, 4-NP removal by using Fe-MABs is higher than MABs due the photo-Fenton degradation process that is already detectable during the first $5 \mathrm{~min}$ of irradiation (see green bar in Fig. 4).

By correlating the estimated values of $\ln \left(\mathrm{PF}[4-\mathrm{NP}]_{t}\right)$ against $t$, we obtained a first order kinetic constant of $k_{\mathrm{PF}}=0.019 \pm 0.002\left(\mathrm{~min}^{-1}\right)$ $\left(R^{2}=0.966\right)$. In theory, the photo-Fenton degradation of 4-NP in the presence of Fe-MABs could be the sum of heterogeneous photoFenton (on the bead's surface) and homogeneous photo-Fenton (from leached iron species in solution); indeed, the obtained value of $k_{\mathrm{PF}}$ is comparable to that reported for solution photo-Fenton of $4-\mathrm{NP}\left(k_{\mathrm{PF}(\mathrm{sin})}=0.023 \mathrm{~min}^{-1}\right)$ determinate by using $1.43 \mathrm{mM}$ of 4-NP, $17.3 \mathrm{mM}$ of $\mathrm{H}_{2} \mathrm{O}_{2}$ and $0.45 \mathrm{mM}$ of $\mathrm{Fe}^{2+}$ [38]. However, during irradiation with $\mathrm{Fe}-\mathrm{MABs}$, photo-Fenton process is detectable already in the first $5 \mathrm{~min}$ when the iron leached in solution is minimal. In fact, to assess metal leaching, we monitored iron content in solution after $60 \mathrm{~min}$ of irradiation for beads amount (Fig. 5a) and during the entire irradiation time for 25 beads (Fig. 5b). Although iron was continuously leached from the beads, its maximum concentration reached $0.6 \mathrm{ppm}$ after $60 \mathrm{~min}$ of irradiation (Fig. 5b), a value significantly lower than that reported for the leaching of Fe-alginate beads $(2.5 \mathrm{ppm})$ used in heterogeneous photo-Fenton [23].
Additionally, the iron concentration on Fe-MABs surface would be much higher than that leached even after $60 \mathrm{~min}$ (10,500 ppm vs $0.6 \mathrm{ppm}$ ). Finally, in the $\mathrm{pH}$ range observed during the first $10 \mathrm{~min}$ (Fig. 2c), the iron in solution would not be present in the form required to promote the homogeneous photo-Fenton [13]. This supports our hypothesis that 4-NP degradation process using FeMABs is mostly due to a heterogeneous photo-Fenton process.

\subsection{Optimization of operational conditions for 4-NP photodegradation with $\mathrm{Fe}-\mathrm{MABS}$}

The operational conditions for the photodegradation of 4-NP over Fe-MABs have been optimized by considering (i) the amount of photocatalyst (Table 2), and (ii) the initial concentration of hydrogen peroxide (Table 3 ).

The catalytic efficiency was evaluated as a function of the dry weight of added catalyst by considering $\mathrm{H}_{2} \mathrm{O}_{2}$ consumption and 4-NP degradation. Irradiation experiments were performed at
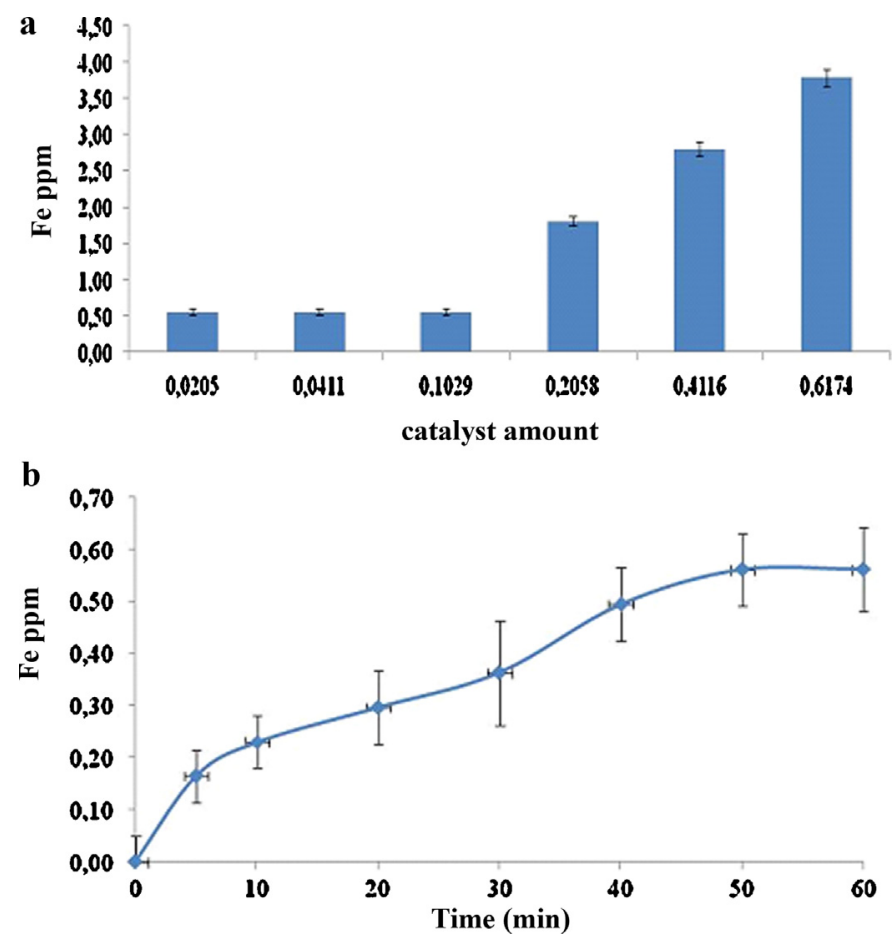

Fig. 5. (a) Amount of iron leached after $60 \mathrm{~min}$ of irradiation as a function of FeMABs amount. (b) Iron leached in solution during 4-NP degradation process using $0.103 \mathrm{mg}$ of Fe-MABs 25 beads $\left(\mathrm{pH}_{i}=7,\left[4-\mathrm{NP}_{0}=10 \mathrm{mg} \mathrm{L}^{-1},\left[\mathrm{H}_{2} \mathrm{O}_{2}\right]=176 \mathrm{mM}\right)\right.$. 
initial $\mathrm{pH}=7.0$ with a starting $10 \mathrm{ppm}$ concentration of $4-\mathrm{NP}$ and $150 \mathrm{ppm}$ of hydrogen peroxide.

Under the same conditions, we also evaluated iron leaching after 60 min of irradiation and as a function of the used amount of catalyst (Fig. 5b).

While $\mathrm{H}_{2} \mathrm{O}_{2}$ consumption constantly increased with the amount of catalyst, due to the increased amount of active sites and degradative processes, the 4-NP degradation was not positively affected by using more than 25 beads of Fe-MABs (see Table 2). This can be justified by considering that alginate itself can scavenge produced ROS and compete with 4-NP for the photodegradation [39]. This hypothesis is also supported by the increased amount of leached iron occurring when the alginate component of the beads starts to photodegrade.

Therefore, the optimal catalyst amount to avoid competing alginate oxidation processes is $0.103 \mathrm{~g}$ (approx 25 beads) in $25 \mathrm{~mL}$.

The effect of initial $\mathrm{H}_{2} \mathrm{O}_{2}$ concentration was instead evaluated by considering only the 4-NP degradation (Table 3 ).

In all cases the 4-NP degradation seems to stop after about $40 \mathrm{~min}$, while the hydrogen peroxide still continues to be consumed (data not shown). It is possible to explain these results considering the competitive reaction of hydroxyl radical; there is competing oxidation of both alginate and formed 4-NP degradation products (4-nitrocatechol and hydroquinone), which have been detected after 20 min of irradiation and can be further oxidized into succinic and oxalic acids.

Interestingly, 4-NP degradation was complete after $40 \mathrm{~min}$ of irradiation in the presence of 500 ppm of $\mathrm{H}_{2} \mathrm{O}_{2}$. However, these cannot be considered as optimal conditions since a significant amount of iron is released in solution with this high concentration of $\mathrm{H}_{2} \mathrm{O}_{2}$ likely because of beads oxidative degradation (see Table 3 ).

Therefore, in order to avoid iron as a secondary contaminant in solution, a $150 \mathrm{ppm}$ initial concentration of hydrogen peroxide has been identified as optimal operating condition for the photodegradation of $4-\mathrm{NP}(10 \mathrm{ppm})$ over Fe-MABs. In fact, the efforts to maintain the structural integrity of the beads, by avoiding iron leaching and alginate degradation, would be paid back by the possibility to recycle the beads for further photodegradative processes.

Table 2

4-NP percentage removal and Fe leached after $60 \mathrm{~min}$ of irradiation using different amounts of Fe-MABs at initial $\mathrm{pH}_{0}=7.0,[4-\mathrm{NP}]_{0}=2.8 \mathrm{mM}(10 \mathrm{ppm})$, $\left[\mathrm{H}_{2} \mathrm{O}_{2}\right]_{0}=0.176 \mathrm{M}(150 \mathrm{ppm})$.

\begin{tabular}{clc}
\hline$[\mathrm{Fe}-\mathrm{MABs}](\mathrm{g} / \mathrm{L})$ & \%4-NP degraded $( \pm 1 \%)$ & {$[\mathrm{Fe}]\left(\mathrm{mg} \mathrm{L}^{-1}\right)$} \\
\hline 0.8 & 23 & $<0.07$ \\
1.6 & 55 & 0.15 \\
4.0 & 75 & 0.23 \\
8.0 & 60 & 0.30 \\
16.0 & 54 & 0.36 \\
24.0 & 45 & 0.50 \\
\hline
\end{tabular}

Table 3

4-NP percentage removal and Fe leached after $60 \mathrm{~min}$ of irradiation using different $\mathrm{H}_{2} \mathrm{O}_{2}$ concentration with $25 \mathrm{Fe}-\mathrm{MABs}$ at initial $\mathrm{pH}_{0}=7.0,[4-\mathrm{NP}]_{0}=2.8 \mathrm{mM}(10 \mathrm{ppm})$.

\begin{tabular}{ccl}
\hline$\left[\mathrm{H}_{2} \mathrm{O}_{2}\right]\left(\mathrm{mg} \mathrm{L}^{-1}\right)$ & \%4-NP degraded $( \pm 1 \%)$ & {$[\mathrm{Fe}]\left(\mathrm{mg} \mathrm{L}^{-1}\right)$} \\
\hline 50 & 30 & 0.50 \\
100 & 55 & 0.56 \\
150 & 75 & 0.56 \\
200 & 77 & 0.96 \\
250 & 88 & 1.29 \\
500 & 100 & 5.25 \\
\hline
\end{tabular}

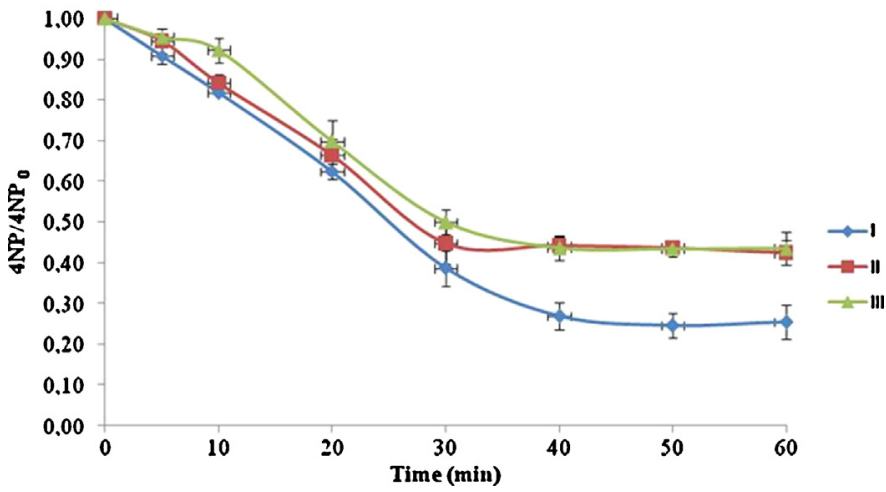

Fig. 6. Recycled of 25 Fe-MABs performance for 4-NP degradation $\left(\mathrm{pH}_{i}=7\right.$, [4$\mathrm{NP}]_{0}=10 \mathrm{ppm},\left[\mathrm{H}_{2} \mathrm{O}_{2}\right]=150 \mathrm{ppm}(0.176 \mathrm{M}):-$ - (blue line) first cycle; $-\boldsymbol{\square}$ - (red line) second cycle; $-\mathbf{\Delta}$ - (green line) third cycle. (For interpretation of the references to color in this figure legend, the reader is referred to the web version of the article.)

Table 4

Recycle proofs for 4-NP percentage removal and Fe leached after $60 \mathrm{~min}$ of irradiation using different $\mathrm{H}_{2} \mathrm{O}_{2}$ concentration with $25 \mathrm{Fe}-\mathrm{MABs}$ at initial $\mathrm{pH}_{0}=7.0$, $[4-\mathrm{NP}]_{0}=2.8 \mathrm{mM}(10 \mathrm{ppm})$.

\begin{tabular}{lll}
\hline Cycle & \%4-NP degraded & {$[\mathrm{Fe}]\left(\mathrm{mg} \mathrm{L}^{-1}\right)$} \\
\hline I & 75 & 0.56 \\
II & 56 & 1.06 \\
III & 56 & 1.39 \\
\hline
\end{tabular}

\subsection{Fe-MABs recyclability}

Since recyclability is one of the important aspects to be considered when dealing with photocatalysis, we performed a preliminary study to assess the possibility to reuse Fe-MABs for further photodegradative processes. In fact, iron-loaded alginate beads are not stable during the photo-Fenton reaction [23], and is not possible to recycle the beads due the total bead degradations after the first treatment step. Recyclability of Fe-MABs was tested over three cycles of 4-NP photodegradation by filtering them from previous experiment and reusing them, without rinsing, in a new photodegradation of a $10 \mathrm{ppm}$ aqueous solution of $4-\mathrm{NP}$. The performance of new and recycled beads was almost identical for the first $30 \mathrm{~min}$ (Fig. 6). After $30 \mathrm{~min}$ the recycled beads showed a lower performance reducing the percentage of 4-NP degradation from $60 \%$ to $50 \%$. However, the performance of beads from the second and third cycle was identical showing that their performance can be assumed as a stable background of catalytic activity (Table 4).

\section{Conclusions}

Experimental studies were conducted to evaluate the efficiency of hybrid iron enriched montmorillonite-alginate beads in the removal of 4-nitrophenol by heterogeneous photo-Fenton reaction under neutral conditions.

Various parameters were studied to establish the optimal conditions for the degradation of $10 \mathrm{ppm}$ aqueous solution of 4-NP $(25 \mathrm{~mL})$. Results pointed out that the catalyst amount ( 25 beads; $0.103 \mathrm{~g}$ ) and the initial hydrogen peroxide concentration ( $150 \mathrm{ppm}$ ) must be carefully chosen to avoid excessive iron leaching and competing degradation of the organic component of the beads. Preliminary recyclability studies evidenced the better stability of Fe-MABs with respect to iron loaded alginate beads thus pointing out Fe-MABs as a promising photocatalyst for the removal of pollutants through environmental friendly photocatalytic processes. 


\section{Acknowledgements}

This work has been supported by Univerità degli Studi di Palermo and Ecole Polytecnique Federale de Lausanne by SwissHungarian Cooperation Programme "Sustainable fine chemical, pharmaceutical industry: screening and utilisation of liquid wastes - Innovative Approaches for the Abatement Industrial/Toxic Waste in Aqueous Effluents.

\section{References}

[1] R. Hammer, J. VanBriesen, L. Levine, Fracking's Wake: New Rules are Needed to Protect Our Health and Environment from Contaminated Wastewater, Natural Resources Defense Council, 2012, May 2012 D:12-05-a.

[2] S.A. Snyder, P. Westerhoff, Y. Yoon, D.L. Sedlak, Pharmaceuticals, personal care products, and endocrine disruptors in water: implications for the water industry, Environ. Eng. Sci. 20 (2003) 449-469.

[3] United Nations, Department of Economic and Social Affairs, Population Division, World Population Prospects: The 2010 Revision, Highlights and Advance Tables. ESA/P/WP.220, 2011.

[4] T. Lai, K. Yong, J. Yu, J. Chen, Y. Shu, C. Wang, High efficiency degradation of 4nitrophenol by microwave-enhanced catalytic method, J. Hazard. Mater. 185 (2011) 366-372.

[5] G. Eichenbaum, M. Johnson, D. Kirkland, P. O’Neill, S. Stellar, J. Bielawne, R. DeWire, D. Areia, S. Bryant, S. Weiner, D. Desai-Krieger, P. Guzzie-Peck, D.C. Evans, A. Tonelli, Assessment of the genotoxic and carcinogenic risks of pnitrophenol when it is present as an impurity in a drug product, Regul. Toxicol. Pharmacol. 55 (2009) 33-42.

[6] Y. Shinozaki, N. Kimura, T. Nakahara, Difference in degrading p-nitrophenol between indigenous bacteria in a reactor, J. Biosci. Bioeng. 93 (2002) 512-514.

[7] A.A.M. Daifullah, B.S. Girgis, Removal of some substituted phenols by activated carbon obtained from agricultural waste, Water Res. 32 (1998) 1169-1177.

[8] N. Nakada, T. Tanishima, H. Shinohara, K. Kiri, H. Takada, Pharmaceutical chemicals and endocrine disrupters in municipal wastewater in Tokyo and their removal during activated sludge treatment, Water Res. 40 (2006) 3297-3303.

[9] A. Ely, M. Baudu, M.O.S.A.O. Kankoub, J.P. Basly, Copper and nitrophenol removal by low cost alginate/Mauritanian clay composite beads, Chem. Eng. J. 178 (2011) 168-174.

[10] E. Pino, M.V. Encinas, Photocatalytic degradation of chlorophenols on $\mathrm{TiO}_{2}$ 325 mesh and $\mathrm{TiO}_{2}-\mathrm{P} 25$. An extended kinetic study of photodegradation under competitive conditions, J. Photochem. Photobiol. A 15 (2012) 20-27.

[11] A. Pace, S. Barreca, Recent advances in environmental organic and bio-organic chemistry, Curr. Org. Chem. 17 (2013) 3032-3041.

[12] S. Barreca, S. Orecchio, A. Pace, Photochemical sample treatment for extracts clean up in PCB analysis from sediments, Talanta 103 (2013) 349-354.

[13] J.J. Pignatello, E. Oliveros, A. MacKay, Advanced oxidation processes for organic contaminant destruction based on the Fenton reaction and related chemistry, Crit. Rev. Environ. Sci. Technol. 36 (2006) 1-84.

[14] I. Oller, S. Malato, J.A. Sánchez-Pérez, Combination of advanced oxidation processes and biological treatments for wastewater decontamination-a review, Sci. Total Environ. 409 (2011) 4141-4166.

[15] J. Fernandez, J. Bandara, A. Lopez, P. Alberz, J. Kiwi, Efficient photo-assisted Fenton catalysis mediated by Fe ions on Nafion membranes active in the abatement of non-biodegradable azo-dye, Chem. Commun. (1998) 1493-1494.

[16] G.L. Puma, P.L. Yue, Heterogeneous photo-assisted Fenton oxidation of Indigo carmine dye on iron-Nafion pellet, in: Proceedings at the Sixth International Conference on Advanced Oxidation Technologies for Water and Air Remediation, London, Ontario, Canada, 26-30, 2000, p. 105.

[17] J. Feng, X. Hu, P.L. Yue, Degradation of azo-dye Orange II by a photoassited Fenton reaction using a novel composite of iron oxide and silicate nanoparticles as a catalyst, Ind. Eng. Chem. Res. 42 (2003) 2058-2066
[18] J. Herney-Ramirez, Miguel A. Vicente, Luis M. Madeira, Heterogeneous photoFenton oxidation with pillared clay-based catalysts for wastewater treatment: a review, Appl. Catal. B: Environ. 98 (2010) 10-26.

[19] V.V. Ishtchenko, K.D. Huddersman, R.F. Vitkovskaya, Production of a modified PAN fibrous catalyst and its optimisation towards the decomposition of hydrogen peroxide, Appl. Catal. A 242 (2003) 123-137.

[20] Y. Dong, Z. Han, C. Liu, F. Du, Preparation and photocatalytic performance of Fe (III)-amidoximated PAN fiber complex for oxidative degradation of azo dye under visible light irradiation, Sci. Total Environ. 408 (2010) 2245-2253.

[21] J. Fernandez, M.R. Dhananjeyan, J. Kiwi, Evidence for Fenton photoassisted processes mediated by encapsulated Fe ions at biocompatible pH values, J. Phys. Chem. B 104 (2000) 5298-5301.

[22] S. Cataldo, A. Gianguzzaa, A. Pettignano, I. Villaescusa, Mercury(II) removal from aqueous solution by sorption onto alginate, pectate and polygalacturonate calcium gel beads. A kinetic and speciation based equilibrium study, React. Funct. Polym. 73 (2013) 207-217.

[23] Y. Dong, W. Dong, Y. Cao, Z. Han, Z. Ding, Preparation and catalytic activity of Fe alginate gel beads for oxidative degradation of azo dyes under visible light irradiation, Catal. Today 175 (2011) 346-355.

[24] O. Iglesias, J. Gómez, M. Pazos, M.Á. Sanromán, Electro-Fenton oxidation of imidacloprid by Fe alginate gel beads, Appl. Catal. B: Environ. 144 (2014) 416424.

[25] L. Liu, Y. Wana, Y. Xie, R. Zhai, B. Zhang, J. Liu, The removal of dye from aqueous solution using alginate-halloysite nanotube beads, Chem. Eng. J. 187 (2012) 210-216.

[26] G. Cavallaro, A. Gianguzza, G. Lazzara, S. Milioto, D. Piazzese, Alginate gel beads filled with halloysite nanotubes, Appl. Clay Sci. 72 (2013) 132-137.

[27] L. Chirchi, A. Ghorbel, Use of various Fe-modified montmorillonite samples for 4-nitrophenol degradation by $\mathrm{H}_{2} \mathrm{O}_{2}$, Appl. Clay Sci. 21 (2002) 271-276.

[28] B. Arjunan, M. Karuppan, Treatment of phenol-containing wastewater by photoelectro-Fenton method using supported nanoscale zero-valent iron, Environ. Sci. Pollut. Res. 20 (2013) 1596-1605.

[29] A. Ely, M. Baudu, J.P. Basly, M.O.S.A.O. Kankou, Copper and nitrophenol pollutants removal by Na-montmorillonite/alginate microcapsules, J. Hazard. Mater. 171 (2009) 405-409.

[30] I. Muthuve, B. Krishnakumar, M. Swaminathan, Novel Fe encapsulated montmorillonite K10 clay for photo-Fenton mineralization of Acid Yellow 17, Indian J. Chem. 51 (2012) 800-806

[31] K. Ebitani, M. Ide, T. Mitsudome T. Mizugaki, K. Kaneda, Creation of a chainlike cationic iron species in montmorillonite as a highly active heterogeneous catalyst for alkane oxygenations using hydrogen peroxide, Chem. Commun. (2002) 690-691.

[32] J.P. Paques, E. Van der Linden, C.J.M. van Rijn, L.M.C. Sagis, Alginate submicron beads prepared through w/o emulsification and gelation with $\mathrm{CaCl}_{2}$ nanoparticles, Food Hydrocolloids 31 (2013) 428-434.

[33] P. Gharbani, M. Khosravi, S.M. Tabatabaii, K. Zare, S. Dastmalchi, A. Mehrizad, Degradation of trace aqueous 4-chloro-2-nitrophenol occurring in pharmaceutical industrial wastewater by ozone, Int. J. Environ. Sci. Technol. 7 (2010) 377-384.

[34] P. Cambier, Infrared study of goethites of varying crystallinity and particle size: I. Interpretation of $\mathrm{OH}$ and lattice vibration frequencies, Clay Miner. 21 (1986) $191-200$.

[35] E. Lipczynska-Kochany, Degradation of nitro-benzene and nitrophenols by means of advanced oxidation processes in the presence of hydrogen peroxide versus the Fenton reaction, Environ. Technol. 24 (1992) 1369-1380.

[36] H.C. Urey, L.H. Dawsey, F.O. Rice, The adsorption spectrum and decomposition of hydrogen peroxide by light, J. Am. Chem. Soc. 51 (1927) 1371-1383.

[37] A.E. Beg, The effect of $\mathrm{pH}$ and various additives on extinction coefficients for nitrophenol, J. Chem. Soc. Pak. 6 (1984) 55-61.

[38] V. Kavitha, K. Palanivelu, Degradation of nitrophenols by Fenton and photo-Fenton processes, J. Photochem. Photobiol. A: Chem. 170 (2005) 83-95.

[39] E. Lipczynska-Kochany, Novel method for photocatalytic degradation of 4nitrophenol in homogeneous aqueous solution, Environ. Technol. 12 (1991) 87-92. 